increased with the level of use of the coat, and coats that are used less frequently may require correspondingly longer to attain the steady state of microbial contamination. The white coats that were judged to be dirty did not differ in the level or type of microbial contamination from the clean white coats, which suggests that appearance does not necessarily indicate the degree of microbial colonisation.

The isolation of $S$ aureus from a white coat is related to personal carriage, as $48 \%$ of the doctors from whose coats $S$ aureus was isolated carried the organism in their noses. However, $S$ aureus was more likely to be isolated from the coats of doctors in some specialties, especially surgical specialties. Therefore, potential does exist for cross infection in surgical areas, particularly during examination of wounds postoperatively, although there was no evidence of such cross infection from this study.

Pathogenic Gram negative bacteria were not isolated in this study and were reported infrequently in other studies. ${ }^{49}$ This may be due to the fact that many of these organisms need a warm moist environment for survival, which is not present on the white coats. It was not within the scope of this study to assess viral contamination of the coats, although it is known that several common viruses, such as enteroviruses and small round structured viruses, survive well within the environment and may be transmitted by fomites.

Some conclusions can be drawn from this study. There is little microbiological reason for recommending a more frequent change of white coat than once a week. However, there is potential for cross infection with $S$ aureus, particularly among the surgical specialties. During clinical examinations the cuffs of white coats come into frequent close contact with patients' clothing and skin, at which point bacteria may be both acquired from and transferred to the patient. White coats with close fitting cuffs might help to reduce this problem, although it may be better to remove the white coat and put on a plastic apron before examining wounds. Also, as contamination of the hands is highly likely to occur from organisms present on the cuff, 0 and vice versa, scrupulous hand washing should be observed before and after attending patients. Finally, this study contains minimal microbiological evidence? to support the exclusion of white coats from non-o clinical areas of the hospital such as libraries and dining rooms.

We thank Dr J Kavi and other colleagues at the Regionalo Public Health Laboratory at East Birmingham Hospital for their technical help and advice. We also thank the Staphylo- $\bigcirc$ coccus Reference Unit at the Central Public Health Laboratory for carrying out the phage typing on the $S$ aureus isolates.

1 Lidwell OM, Towers AG, Ballard J. Transfer of microorganisms between nurses and patients in a clean air environment. $\mathcal{F}$ Appl Bacteriol 1974;37: 649-56.

2 Ransio U. Attempts to control clothes-borne infection in a burns unit. $2 \infty$ Clothing routines in clinical use and the epidemiology of cross-colonization

Journal of Hygiene 1979;82:369-84.
3 Speers R, Shooter RA, Gaya H, Patel N, Hewitt JH. Contamination of nurses' uniforms with Staphylococcus aureus. Lancet 1969;ii:233.

4 Babb JR, Davies JG, Ayliffe GA. Contamination of protective clothing and nurses' uniforms in an isolation ward. $\mathcal{F}$ Hosp Infect 1983;4:149-57.

5 Hambraeus A. Transfer of Staphylococcus aureus via nurses' uniforms. N fournal of Hygiene 1973;71:799-814.

6 Nystrom B. The contamination of gowns in an intensive care unit. $\mathcal{f}$ Hosp Infect $\square$ $1981 ; 2: 167-70$

7 Nicoles PS. Bacteria in laundered fabrics. Am f Public Health 1970;60:2175

8 Ayliffe GAJ, Collins BJ, Lowbury EJC, Babb JR, Lilly HA. Ward floors and other surfaces as reservoirs of hospital infection. Journal of Hygiene 1967;65: 515-36.

9 Robinton ED, Mood EW. A study of bacterial contaminants of cloth and paper towels. Am F Public Health 1968;58:1452.

\title{
Do pathologists have extrasensory perception?
}

\author{
A D Bull, S S Cross, D S James, P B Silcocks
}

Extrasensory perception (ESP) may be defined as the divination of knowledge without recourse to the appreciation of light, sound, temperature, or movement. This talent has been recognised in some of the earliest cultures and has been considered both a gift and a curse; a sign of virtue or of evil, of deity or of devilry. It has been attributed to witches, prophets, necromancers, soothsayers, and clairvoyants, and it has been used for religious, political, sociosexual, and sporting purposes. Almost without exception the possession of this ability has lent fame, fortune, and notoriety to its owner. The exception is the histopathologist, who nevertheless has long been held by all medical practitioners to be a master of this art.

In early medical practice the physician was able to divine the imbalance of the four humours-phlegm, blood, black bile, and yellow bile - and thereby ascertain the nature of a disease and its cure. With such a long history of divination as an integral part of medicine it is hardly surprising that when Giovanni Battista Morgagni began the medical renaissance by relating morbid anatomy to symptoms and signs in his patients, ${ }^{12}$ therefore removing the need for the divination of the humours, that the art was transferred to his descendants, the histopathologists, who were considered able to divine the symptoms and signs from the morbid anatomical findings alone.

The current vogue for clinical audit has not approached the assessment of this aspect of pathological practice. Indeed, it is not mentioned once in the government's white paper. We consider that this omission should be made good and the clairvoyant ability of the histopathologist be properly tested.

\section{Method and results}

A total of 48 histological sections of basal cell carcinomas from two men and two women born under? each of the 12 star signs, matched within five years of 0 age, was screened to exclude features that might give as clue to gender, such as Oil of Ulay and sycosis barbae. The slides were coded and circulated in random order to a mixed group of 10 pathologists for assessment of sex and star signs. The pathologists examined the ${ }^{\omega}$ sections under low power magnification only (up to $100 \times$ total magnification) to prevent the recognition of sex by Barr bodies.

To assess the correctness of observers' ratings a $\varkappa$ type of statistic was derived from the statistic described by Light for testing the agreement of observers with a standard. ${ }^{3} x$ Statistics were also used to measure the degree of interobserver agreement. ${ }^{4}$ In both cases a bootstrap method was used to estimate the confidence intervals. ${ }^{5}$ These intervals were calculated in two ways: firstly, for this particular group of pathologists (fixed observers) and, secondly, for pathotôे logists in general (random observers), based on the assumption that this particular group is a random sample from the pool of potential observers. A $x$ value of 1.0 indicates perfect agreement, zero indicates 
$\varkappa$ Values for correct identification and interobserver agreement. Values in parentheses are proportions of ratings observed/expected to be in agreement; confidence intervals were based on 1500 bootstrap samples

\begin{tabular}{lll}
\hline & Correct identification & \multicolumn{1}{c}{$\begin{array}{c}\text { Interobserver } \\
\text { agreement }\end{array}$} \\
\hline Sex & $+0.0625(0.531 / 0.500)$ & $+0.0116(0.506 / 0.500)$ \\
$95 \%$ Confidence interval: & -0.070 to 0.072 & -0.134 to 0.158 \\
$\quad$ Fixed observer & -0.092 to 0.089 & -0.096 to 0.312 \\
Random observer & $+0.005(0.0875 / 0.0833)$ & $-0.007(0.0777 / 0.0841)$ \\
Star sign & -0.024 to 0.026 & -0.012 to 0.085 \\
95\% Confidence interval: & -0.060 to 0.223 \\
\hline
\end{tabular}

chance agreement, and negative values indicate disagreement.

The table shows the extent that observers were correct and the interobserver agreement.

\section{Comment}

The results of this study show that the likelihood of this particular group of pathologists or pathologists in general being capable of divining the sex or star sign of a patient, even with recourse to the perception of light, is no greater than chance. From this it is reasonable to deduce that pathologists do not possess extrasensory perception, at least as far as medical practice is concerned.

In the light of these findings clinical practice should now radically alter. We strongly recommend that physicians, surgeons, and other users of histopathological services change their current practice and provide full clinical information on all request forms.

We thank our colleagues in the department of pathology, Sheffield University Medical School, for their help in this research.

\footnotetext{
Underwood JCE. Introduction to biopsy interpretation and surgical pathology. London: Springer-Verlag, 1987:2-3.

Lyons AS, Petrucelli RJ. Medicine: an illustrated history. New York: Abrams, 1987:583.

3 Light RJ. Measures of response agreement: some generalisations and alternatives. Psychol Bull 1971;76:365-77.

4 Fleiss JL. Statistical methods for rates and proportions. 2nd ed. New York: John Wiley, 1981:230.

5 Diaconis P, Efron B. Computer intensive methods in statistics. Sci Am 1983;248(5):6-108.
}

\section{How to have a fever of unknown origin}

Miles Burrows

I was working in the Middle East and had never felt so fit in my life. I played tennis in the warm nights under the floodlights and in the day swam up and down the pool like a trout in a restaurant. I even gave myself extra pocket money by donating my blood for the blood transfusion service.

When one day they told me that they could not accept my blood I felt a little offended-rather as an author would feel if his poems were rejected by a magazine, but otherwise I thought nothing of it. I went on swimming up and down the pool. But I got messages that there was something wrong with my white cells. They kept going down.

I was feeling so well that again I thought nothing of it, even felt that having a low white count could be a sign of being superfit, like having a slow pulse. Then I started feeling rather tired and even found it difficult to stand for long periods, especially in the hot sun waiting for the bus to the hospital. I would hunker down under the pipul tree like a Pathan gardener. At nights I was woken by the sound of the bedhead knocking against the wall. This was not a wet dream, but it was caused by my heart beating rapidly and strongly as I slept. Every time I checked my white cells they had gone further down. When other doctors told me to take this seriously I saw the haematologist.

He was an American. He told me that the white cells looked as if they were turned on. I was impressed by the phrase "turned on," which sounded up to date, even hip. He said that he was going on holiday, that these things could be caused by a virus, so we should wait. I agreed, but felt weaker and weaker.

I consulted a general physician, who agreed with me that this could be a "leukaemic process." He did a sternal marrow tap in my own consulting room in the hospital in the lunch break. I was spreadeagled on the couch with the needle aimed far too close to the heart. When the result came back - "a dry tap"-this confirmed our fears. I went upstairs, where the oncologist did a biopsy of the iliac crest. I waited numbly for the pathologist's report, like a man doing a crossword while his plane is crashing. When the result came back as normal I was astonished. But we had to suppose that that ruled out leukaemia.

\section{Loss of weight}

When it was time to go back to England on holiday I could hardly carry my backpack. I sat in a window seat on the plane warming myself in the sunlight like a fly, and refused to give up my seat for a child. When my wife saw me she hardly recognised me. I had lost $10 \mathrm{~kg}$. I went to my general practitioner and told him I thought I should go to hospital as an emergency. He agreed and asked me if I wanted to go in under oncology or infectious diseases. I already had a letter in my pocket that I had written to the professor of haematology or oncology, but then thought why not try infectious diseases?

I went into the infectious diseases unit through a decontamination area like something out of a space shuttle. Everyone was wearing masks so they couldn't catch whatever it was I had got. It made them look like symbolic figures in a Japanese play. They gave me quinine for malaria. It was the consultant's doctrine that all exotic fevers were caused by malaria.

$\mathrm{My}$ fevers rose to $40^{\circ} \mathrm{C}$ at night and I was sweating like an Ascot winner. The registrar would come in and say, "You had an impressive fever last night," as if congratulating me on having hit a six. They tested for brucellosis and asked if I had been drinking goat's milk.

I drank aniseed flavoured dyes and was pushed around in a wheelchair at high speed from one scanner to the next, feeling like an elderly art critic being wheeled round an exhibition just before the deadline for his copy - the corridors were hung with attractive original paintings. At the back of my mind I was worried that I had some form of AIDS and I mentioned this to the consultant. AIDS had already been screened out in the Middle East, but I kept thinking of that time in Bangkok. That girl who rode a water buffalo in high heeled shoes. I remembered trying to persuade her to wear sensible shoes. I thought of her as I looked out of the locked fire escape on the ninth floor. When after a 